\title{
Metabolomics Based on UPLC-QTOF/MS Applied for the Discrimination of Cynanchum wilfordii and Cynanchum auriculatum
}

Lee Jae-Won', Ji Seung-Heon', Lee Mi-Kyoung ${ }^{2}$, Kim Geum-Soog ${ }^{1}$, Ahn Young-Sup', Ko Hee-Jung ${ }^{3}$, Baek Nam-In ${ }^{4}$ and Lee Dae-Young $^{1 *}$

${ }^{1}$ Department of Herbal Crop Research, National Institute of Horticultural and Herbal Science, RDA, Eumseong 27712, Republic of Korea

${ }^{2}$ Cancer Preventive Material Development Research Center, College of Oriental Medicine, Kyung Hee University, Seoul 02453, Republic of Korea

${ }^{3}$ Waters Corporation, Seoul 07241, Republic of Korea

${ }^{4}$ Department of Oriental Medicinal Materials and Processing, Kyung Hee University, Yongin 17104, Republic of Korea

\begin{abstract}
Recently, it has been a big issue to distinguish the dried roots of Cynanchum wilfordii and Cynanchum auriculatum in Korean herbal medicine market. Although $C$. wilfordii and $C$. auriculatum have similar morphology, the types and quantities of metabolites may differ depending on the species. Thus, in this study, UPLC-QTOF/MS based metabolomics was applied to discriminate the roots of $C$. wilfordii and $C$. auriculatum. In the optimal LC/MS conditions, 64 known metabolites were analyzed in the two species. PCA and PLS-DA of metabolic profile data was able to differentiate between C. wilfordii and C. auriculatum. Furthermore, OPLS-DA and S-plot were applied to find the potential biomarkers for the discrimination of $C$. wilfordii and $C$. auriculatum. Finally, 4 known and 10 unknown metabolites were determined as the biomarkers, and their repeatability and reliability were also validated. This indicated the metabolite profiling is a robust approach to find discriminating biomarkers of $C$. wilfordii and $C$. auriculatum.
\end{abstract}

Keywords: Cynanchum wilfordii; Cynanchum auriculatum; Metabolomics; UPLC-QTOF/MS; PCA; PLS-DA; OPLS-DA

\section{Abbreviations}

UPLC-QTOF/MS: Ultra-Performance Liquid Chromatography Coupled with Quadrupole Time-of-Flight/Mass Spectrometry; PCA: Principal Component Analysis; PLS-DA: Partial Least SquareDiscriminant Analysis; OPLS-DA: Orthogonal Partial Least SquareDiscriminant Analysis

\section{Introduction}

The roots of Cynanchum wilfordii and Cynanchum auriculatum have been widely used as traditional herbal medicines in Eastern Asia. C. wilfordii is an ingredient for tonic herbal drugs, and it shows pharmaceutical benefits against tumors, antioxidants, vascular diseases, and diabetes mellitus [1-4]. In China, C. auriculatum has been used as a tonic agent having the activities of anti-tumor, gastroprotective, antidepressant, and anti-aging [5-7]. However, in Korea, the human consumption of $C$. auriculatum is still not approved due to its safety concerns. Thus, only the $C$. wilfordii is registered in Korean Herbal Pharmacopoeia [8].

C. wilfordii and C. auriculatum belong to the Asclepiadaceae family and appear morphologically similar. In order to discriminate them, it is needed to find the presence of sap and the leaf shapes: C. auriculatum has a blade ovate leaf comparing to C. wilfordii [9]. However, in the herbal medicine market, they have been handled as cut and dried roots. Due to their similar morphology, it is limited to distinguish the roots of C. wilfordii and C. auriculatum. Recently in Korea, it has been a critical issue to misuse these two roots in the herbal market and food industry [10]. Thus, it is required to establish a robust tool for the discrimination and quality control of them.

In order to discriminate C. wilfordii and C. auriculatum, several analytical methods have been previously reported. HPLC-UV method was used to analyze eight marker compounds including conduritol $\mathrm{F}$ to discriminate the two species [11]. Phytochemical study was also performed to discover effective chemical markers for their identification [12]. Furthermore, multiplex polymerase chain reaction with specific primers was tried to perform the molecular authentication of similar medicinal plant species [13,14].
Recently, metabolomics based on liquid chromatography (LC) coupled with mass spectrometry (MS) have been used to assess the contents of plant metabolites $[15,16]$. Plants produce various metabolites in response to developmental, environmental, and stressinduced physiological changes [17-19]. In particular, metabolite profiling by LC/MS is an emerging tool to phenotype and evaluate the quality of plants [20-23]. In this study, we applied the ultra-performance liquid chromatography (UPLC) coupled with quadrupole time-offlight (QTOF)/MS to analyze various metabolites in the roots of $C$. wilfordii and C. auriculatum. Their metabolic profile data was subjected to several multivariate analysis including principal component analysis (PCA), projection to latent structure discriminant analysis (PLS-DA), and orthogonal projections to latent structures discriminant analysis (OPLS-DA) to observe the dissimilarities of metabolites between $C$. wilfordii and $C$. auriculatum. Finally, significant metabolites were selected as the biomarkers to differentiate two species.

\section{Materials and Methods}

\section{Herbal medicine samples and reagents}

Dried one-year old Cynanchum wilfordii (CW) and Cynanchum auriculatum (CA) roots were purchased from Yeongju, Gyeongbuk Province, South Korea in 2014. Voucher specimen (NIHHS2014-3) was deposited at the herbarium of the Department of Herbal Crop Research, National Institute of Horticultural and Herbal Science, RDA, Eumseong, Korea. HPLC-grade acetonitrile, methanol, and water were obtained from Merck (Darmstadt, Germany). Formic acid was purchased from Sigma-Aldrich (St. Louis, MO, USA).

*Corresponding author: DY Lee, Department of Herbal Crop Research, National Institute of Horticultural and Herbal Science, RDA, Eumseong 27712 Republic of Korea, Tel: 82-63-238-6000; E-mail: dylee0809@korea.kr

Received September 28, 2015; Accepted October 08, 2015; Published October 10, 2015

Citation: Lee JW, Ji SH, Lee MK, Kim GS, Ahn YS, et al. (2015) Metabolomics Based on UPLC-QTOF/MS Applied for the Discrimination of Cynanchum wilfordii and Cynanchum auriculatum. Metabolomics 5: 152. doi:10.4172/21530769.1000152

Copyright: ( 2015 Lee JW, et al. This is an open-access article distributed under the terms of the Creative Commons Attribution License, which permits unrestricted use, distribution, and reproduction in any medium, provided the original author and source are credited. 


\section{Sample preparation}

Each root sample was dried at $35^{\circ} \mathrm{C}$ in a forced-air-convection-drying oven for three days after washing, and then weighed. The roots were ground $(<0.5 \mathrm{~mm})$ using a mixer (Hanil, Seoul, Korea) and thoroughly mixed, after which the subsamples were homogenized further using a Retsch MM400 mixer mill (Retsch GmbH, Haan, Germany) for the analyses. Fine powder was weighed $(50 \mathrm{mg})$, suspended in $10 \mathrm{~mL}$ of $70 \%(\mathrm{v} / \mathrm{v})$ methanol, and ultrasonically extracted for $1 \mathrm{~h}$ at $50^{\circ} \mathrm{C}$. The extract was filtered and evaporated in a vacuum, and the residue was dissolved in $70 \%$ methanol. The solution was filtered through a syringe filter $(0.22 \mu \mathrm{m})$ and injected directly into the UPLC system.

\section{UPLC-QTOF/MS analysis}

UPLC was performed using a Waters ACQUITY H-Class UPLC (Waters Corp.). Chromatographic separations were performed on an ACQUITY BEH C18 column $(2.1 \mathrm{~mm} \times 100 \mathrm{~mm}, 1.7 \mu \mathrm{m})$. The column oven was maintained at $40^{\circ} \mathrm{C}$ and the mobile phases consisted of solvent A [0.1\% formic acid $(\mathrm{v} / \mathrm{v})$ in water] and solvent B [0.1\% formic acid $(\mathrm{v} / \mathrm{v})$ in acetonitrile]. The gradient elution program was as follows: $0-2$ min, B 10-40\%; 2-3.5 min, B 40-45\%; 3.5-4.2 min, B 45-55\%; 4.2-4.8 min, 55-65\%; 4.8-5.2 min, 65-70\%; 5.2-10 min, B 70-100\%; 10-11 min, B $100-10 \% ; 11-13 \mathrm{~min}, \mathrm{~B} 10 \%$. The flow rate was $450 \mu \mathrm{L} / \mathrm{min}$ and $2 \mu \mathrm{L}$ aliquot of each sample was injected onto the column.

Next, MS analysis was performed using a Waters Xevo G2-S QTOF/ MS (Waters Corp.) using an electrospray ionization (ESI) operated in the positive and negative ion mode. The mass spectrometers performed alternative high- and low-energy scans, known as the $\mathrm{MS}^{\mathrm{E}}$ acquisition mode. The operating parameters were as follows: cone voltage, $40 \mathrm{~V}$; capillary voltage, $3.0 \mathrm{kV}$; source temperature, $120^{\circ} \mathrm{C}$; desolvation temperature, $300^{\circ} \mathrm{C}$; cone gas flow, $30 \mathrm{~L} / \mathrm{h}$; and desolvation gas flow, $600 \mathrm{~L} / \mathrm{h}$. The scan mass range was from 100 and 2,000 m/z. The QTOF/ MS data was collected in centroid mode, using the lock spray to ensure accuracy and reproducibility. A concentration of $200 \mathrm{pg} / \mathrm{mL}$ leucine enkephalin was used as lock mass $(m / z 556.2766$ (ESI+), $m / z 554.2620$ (ESI-)). The lock spray frequency was set at $10 \mathrm{~s}$, and the lock mass data were averaged over 10 scans for correction.

\section{Data processing and multivariate analysis}

All $\mathrm{MS}^{\mathrm{E}}$ data were collected and processed within UNIFI 1.7.1 and 1.8 Beta (Waters Corp., Milford, USA). Data within UNIFI 1.7.1 and 1.8 Beta is passed through the apex peak detection and alignment processing algorithms. This enables related ion components to be grouped together and analyzed as a single entity. The intensity of each ion was normalized with respect to the total ion count to generate a data matrix that consisted of the retention time, $\mathrm{m} / \mathrm{z}$ value, and the normalized peak area. Charged species, salt adducts, and fragments are all automatically aligned and grouped. The three-dimensional data including peak number (RT- $m / z$ pair), sample name, and normalized peak areas were exported to the EZinfo software 3.0.3 (UMETRICS) for multivariate analysis such as unsupervised PCA and the supervised PLS-DA and OPLS-DA. The data were mean-centered and Paretoscaled prior to PCA, PLS-DA, and OPLS-DA.

\section{Results and Discussion}

\section{UPLC-QTOF/MS analysis of various metabolites in the roots of $\mathrm{CW}$ and $\mathrm{CA}$}

For the effective profiling of various metabolites in the roots of $\mathrm{CW}$ and CA, we established a metabolomics platform based on UPLC-
QTOF/MS that enables the fast and sensitive analysis with high mass accuracy. Using the optimal UPLC, metabolites extracted using $70 \%$ methanol was separated well in $12 \mathrm{~min}$. Both positive and negative ion modes were estimated for the ESI of molecules. As a result, the positive mode showed poor efficiency of ionization (data not shown), and various metabolites of the two roots were successfully analyzed in the negative mode. Thus, only negative mode analysis was performed in this study. Figure 1 represented the base peak intensity (BPI) chromatograms of various metabolites in the two roots.

Next, we constructed the in-house library to identify the metabolites of CW and CA, analyzed by UPLC-QTOF/MS. In practical, it is limited to assign a number of mass spectrums without the database. Previous studies have already reported the presence of various metabolites in CW and CA $[6,12,24-26]$. Thus, we added the molecular formula of reported compounds into the in-house library. The $\mathrm{m} / \mathrm{z}$ of ions from the raw data of CW and CA was automatically matched to the library compounds. As a result, 69 metabolites were determined with retention time (RT) and mass accuracy (ppm) (Table 1).

\section{PCA and PLS-DA analysis}

To visualize the general clustering trends between $\mathrm{CW}$ and $\mathrm{CA}$, we applied the multiple pattern recognition methods such as PCA and PLS-DA [27]. First, the constructed method was applied for the metabolite profiling of the extracts obtained from three sample groups including 12 CWs, 12 CAs, and 5 tests (CA:CW mixtures $=5: 5,6: 4,7: 3$, 8:2, 9:1 (w/w)). And then, the processed data was analyzed by PCA and PLS-DA in order to classify the metabolic phenotypes of samples and identify the differentiating metabolites. Unsupervised PCA reduces the dimensionalities of complex datasets and provides an overview of all observations, such as groupings, trends, and outliers [28,29]. In the PCA analysis, the score plot of each sample was shown in Figure 2A. Each point represents an individual sample, and the scatter of samples indicates the similarities or differences of metabolic compositions. Samples having similar metabolite contents are clustered together, whereas those having different metabolites are dispersed. In the PCA score plot, two groups of $12 \mathrm{CWs}$ and 12 CAs were separated well. Furthermore, 5 test samples having different ratio of $\mathrm{CW}$ and CA $(50 \%, 60 \%, 70 \%, 80 \%$, and $90 \%$ CA) were scattered between two groups of $\mathrm{CW}$ and CA. However, 5 test samples and CA group were not distinguished clearly. Thus, we also performed the supervised PLSDA to classify the samples. As a result, the PLS-DA score plot (for the first five components, the goodness of fit of the model (R2Y) $=98 \%$, the predictability of the models $(\mathrm{Q} 2)=79 \%)$ reflected a clear separation trend among three groups of $12 \mathrm{CWs}, 12 \mathrm{CAs}$, and 5 tests (Figure 2B). Of 5 test samples, the point of 50\% CA was positioned almost in the middle of both CW and CA groups. Besides, when the percentage of CA was increased from 50 to $90 \%$, each point was closer to CA groups. This indicated that the metabolic profiles are applicable to not only discriminate $\mathrm{CW}$ and $\mathrm{CA}$, but also evaluate the contents ratio of two species.

\section{OPLS-DA analysis}

Next, OPLS-DA analysis was performed to find the potential biomarkers for the discrimination of CW and CA. The OPLS-DA score plot showed the clear separation between these two groups (Figure 3A). The scores $\mathrm{t}$ [1] (x-axis) and to [1] (y-axis) are the two most important variables in summarizing and separating the data. The separation of CW and CA groups was visible in t [1], and the [1] score values showed the variation within each group. Furthermore, S-plot that shows the covariance $p[1]$ and correlation $p$ (corr) [1] between variables and 
A

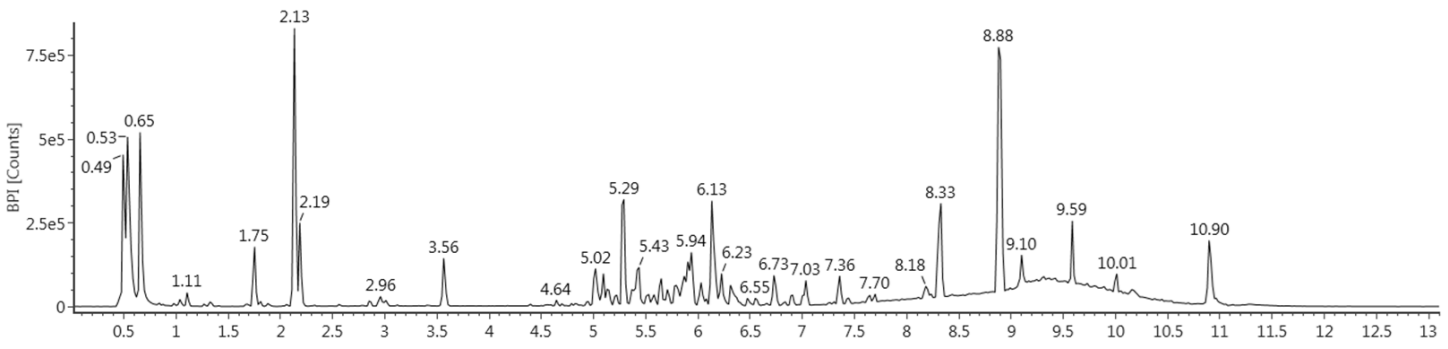

B

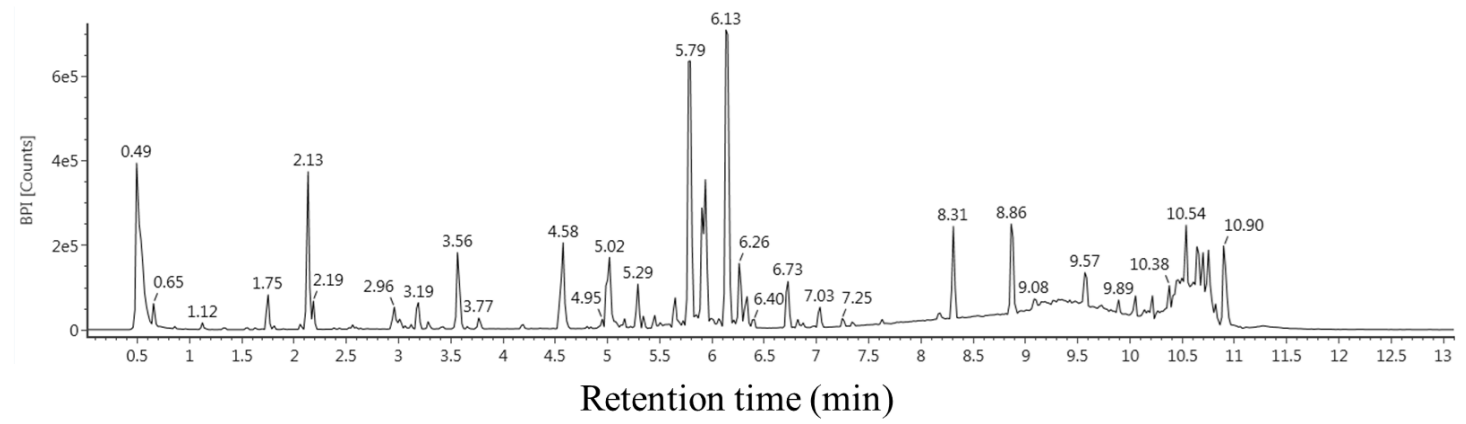

Figure 1: Representative UPLC/QTOF MS-BPI chromatograms of the roots of CW (A) and CA (B) in the negative ion mode.

A

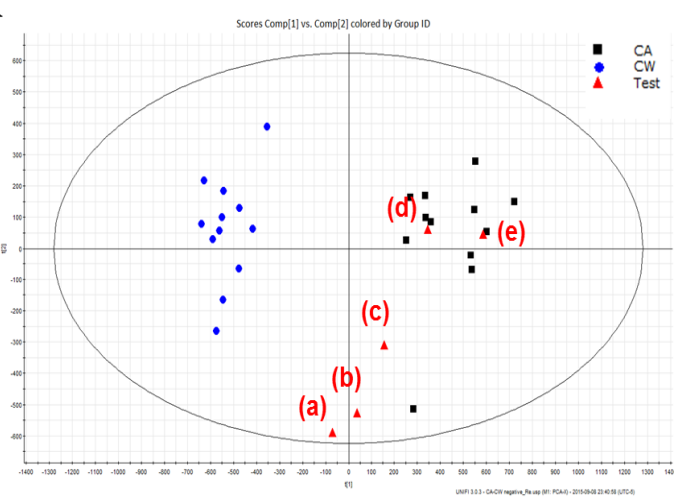

B

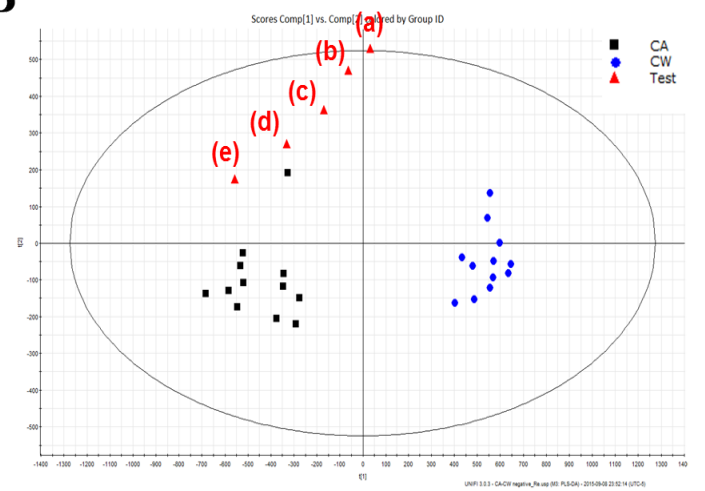

Figure 2: The score plots of PCA (A) and PLS-DA (B) of CA, CW, and Test samples, indicated by boxes, dots, and triangles, respectively. (a) $50 \% \mathrm{CA}$; (b) $60 \% \mathrm{CA}$; (c) $70 \% \mathrm{CA}$; (d) $80 \% \mathrm{CA}$; and (e) $90 \% \mathrm{CA}$.
A

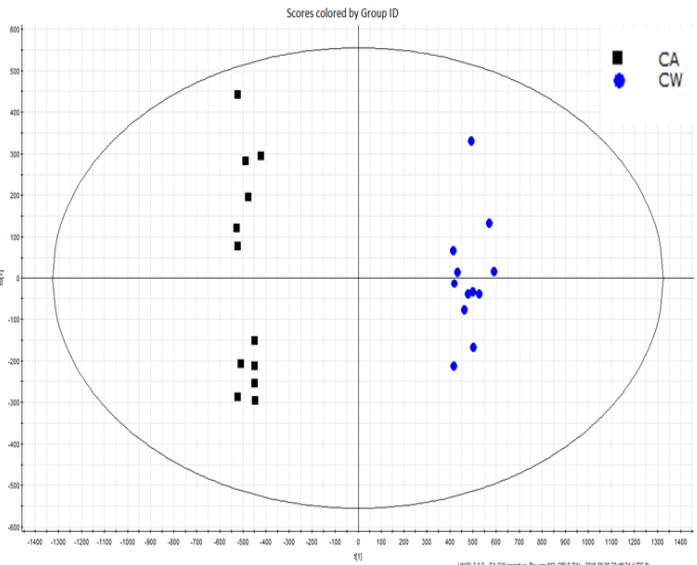

B

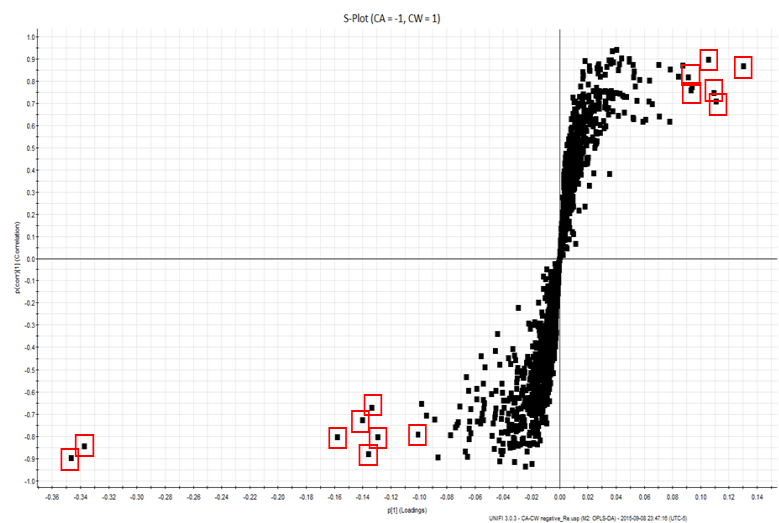

Figure 3: The score plots of OPLS-DA (A) and S-plot (B) of CW and CA samples. 
OPLS-DA model was applied to select the critical variables contributing to differentiate $\mathrm{CW}$ and $\mathrm{CA}$ (Figure 3B). The points in the S-plot represent the $\mathrm{m} / \mathrm{z}$-RT pairs of molecules. The upper right quadrant of the S-plot shows the components elevated in CW, while the lower left quadrant shows the components elevated in CA. When the point is positioned in the farther along the $\mathrm{x}$-axis and $\mathrm{y}$-axis, the metabolite has the greater contribution and higher reliability to the variance between two groups. In the S-plot, several metabolites were selected as the biomarker candidates. And then, we checked the intensities of each metabolite in whole data to monitor their abundantly difference between CW and CA. As a result, 14 metabolites were selected as the biomarkers. The bar graph represented their altered abundances in CW and CA (Figure 4A). In the analysis of $12 \mathrm{CWs}$ and $12 \mathrm{CAs}$, 7 and 4 metabolites were almost uniquely detected in $\mathrm{CW}$ and $\mathrm{CA}$, respectively. In addition, 3 metabolites were detected in both sides, and showed different abundances. This indicated that the 14 metabolites can be useful biomarkers to discriminate $\mathrm{CW}$ and $\mathrm{CA}$.

\section{Identification and validation of selected biomarkers}

Based on the in-house library, we tried to identify the selected 14 biomarkers. As a result, 4 ions with $\mathrm{m} / z$-RT (1201.6001-4.99, 1435.7114-5.443, 1131.5733-5.78, and 1111.6055-6.13) were identified as Cynauricoside E, Wilfoside C1GG (Cynauricoside C), wilfoside K1N, and wilfoside $\mathrm{C} 1 \mathrm{~N}$, respectively. The molecular formula of other 10 ions were also determined by the calculating program, and their RT, mass accuracy, and adducts were listed in Table 2. Next, we performed the validation of 14 biomarkers to find if these biomarkers are repeatable and reliable to discriminate $\mathrm{CW}$ and CA. For this purpose, the biomarkers were analyzed in the additional samples of 6 CWs and 6

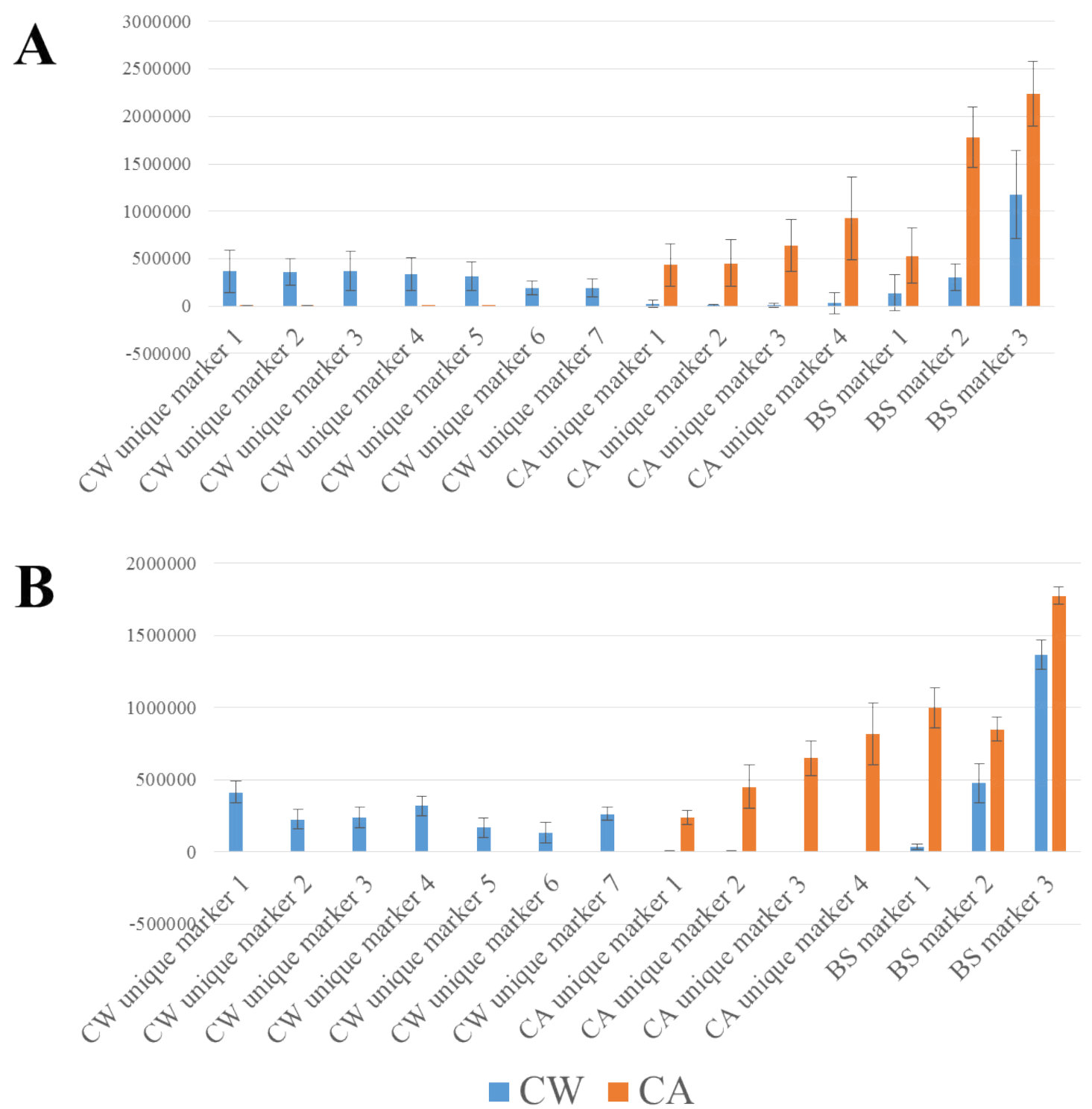

Figure 4: The bar graph of 14 biomarkers altered in CW and CA. 
Citation: Lee JW, Ji SH, Lee MK, Kim GS, Ahn YS, et al. (2015) Metabolomics Based on UPLC-QTOF/MS Applied for the Discrimination of Cynanchum wilfordii and Cynanchum auriculatum. Metabolomics 5: 152. doi:10.4172/2153-0769.1000152

Page 5 of 7

\begin{tabular}{|c|c|c|c|c|c|c|c|c|}
\hline No. & $\mathrm{RT}(\min )$ & Compound names & $\begin{array}{l}\text { Molecular } \\
\text { formula }\end{array}$ & $\begin{array}{l}\text { Expected neutral } \\
\text { mass }(\mathrm{Da})\end{array}$ & $\begin{array}{l}\text { Observed } \\
\text { neutral mass } \\
\text { (Da) }\end{array}$ & $\begin{array}{l}\text { QTOF/MS } \\
\text { (ESI-) } m / z\end{array}$ & $\begin{array}{l}\text { Mass accuracy } \\
(\text { (ppm) }\end{array}$ & Adducts \\
\hline 1 & 0.48 & 20-O-vanilloyl-kidjoranin & $\mathrm{C}_{38} \mathrm{H}_{46} \mathrm{O}_{10}$ & 662.3091 & 662.3075 & 707.3057 & -2.3 & $+\mathrm{HCOO}$ \\
\hline 2 & 0.48 & Geniposide & $\mathrm{C}_{17} \mathrm{H}_{24} \mathrm{O}_{10}$ & 388.1369 & 388.1368 & 433.135 & -0.36 & $+\mathrm{HCOO}$ \\
\hline 3 & 0.48 & Qingyangshengenin & $\mathrm{C}_{28} \mathrm{H}_{36} \mathrm{O}_{8}$ & 500.241 & 500.24 & 545.2382 & -1.79 & $+\mathrm{HCOO}$ \\
\hline 4 & 0.53 & Conduritol F & $\mathrm{C}_{6} \mathrm{H}_{10} \mathrm{O}_{4}$ & 146.0579 & 146.0583 & 191.0565 & 2.23 & $+\mathrm{HCOO}$ \\
\hline 5 & 0.68 & Succinic acid & $\mathrm{C}_{4} \mathrm{H}_{6} \mathrm{O}_{4}$ & 118.0266 & 118.027 & 117.02 & 1.18 & $-H$ \\
\hline 6 & 0.84 & Cynanoneside B & $\mathrm{C}_{14} \mathrm{H}_{18} \mathrm{O}_{8}$ & 314.1002 & 314.1002 & 313.0929 & -0.03 & $-\mathrm{H}$ \\
\hline 7 & 1.76 & $p$-hydroxyacetophenone & $\mathrm{C}_{8} \mathrm{H}_{8} \mathrm{O}_{2}$ & 136.0524 & 136.0524 & 135.0452 & 0 & $-\mathrm{H}$ \\
\hline 8 & 1.82 & Acetovanillone & $\mathrm{C}_{9} \mathrm{H}_{10} \mathrm{O}_{3}$ & 166.063 & 166.0629 & 165.0556 & -0.44 & $-\mathrm{H}$ \\
\hline 9 & 2.03 & Resacetophenone & $\mathrm{C}_{8} \mathrm{H}_{8} \mathrm{O}_{3}$ & 152.0473 & 152.0472 & 151.0399 & -0.98 & $-\mathrm{H}$ \\
\hline 10 & 2.14 & Cynandione A & $\mathrm{C}_{16} \mathrm{H}_{14} \mathrm{O}_{6}$ & 302.079 & 302.079 & 301.0718 & -0.03 & $-\mathrm{H}$ \\
\hline 11 & 2.14 & Scopoletin & $\mathrm{C}_{10} \mathrm{H}_{8} \mathrm{O}_{4}$ & 192.0423 & 192.0409 & 191.0336 & -7.35 & $-\mathrm{H}$ \\
\hline 12 & 2.6 & Penupogenin & $\mathrm{C}_{30} \mathrm{H}_{40} \mathrm{O}_{7}$ & 512.2774 & 512.2773 & 511.27 & -0.25 & $-\mathrm{H}$ \\
\hline 13 & 2.81 & Cynanchone A & $\mathrm{C}_{17} \mathrm{H}_{16} \mathrm{O}_{6}$ & 316.0947 & 316.0947 & 315.0874 & 0.03 & $-\mathrm{H}$ \\
\hline 14 & 2.83 & Cynauricoside $\mathrm{H}$ & $\mathrm{C}_{47} \mathrm{H}_{76} \mathrm{O}_{18}$ & 928.5032 & 928.5058 & 973.504 & 2.66 & $+\mathrm{HCOO}$ \\
\hline 15 & 3.39 & Cynauricoside $\mathrm{F}$ & $\mathrm{C}_{54} \mathrm{H}_{88} \mathrm{O}_{21}$ & 1072.5818 & 1072.5823 & 1117.5805 & 0.45 & $+\mathrm{HCOO}$ \\
\hline 16 & 4.42 & Kidjoranin & $\mathrm{C}_{30} \mathrm{H}_{38} \mathrm{O}_{7}$ & 510.2618 & 510.2664 & 555.2646 & 8.38 & $+\mathrm{HCOO}$ \\
\hline 17 & 4.68 & Cyanoauriculoside A & $\mathrm{C}_{72} \mathrm{H}_{110} \mathrm{O}_{30}$ & 1454.7082 & 1454.7078 & 1499.706 & -0.27 & $+\mathrm{HCOO}$ \\
\hline 18 & 4.78 & Caudatin & $\mathrm{C}_{28} \mathrm{H}_{42} \mathrm{O}_{7}$ & 490.2931 & 490.2932 & 535.2914 & 0.25 & $+\mathrm{HCOO}$ \\
\hline 19 & 4.81 & Cynanauriculoside E & $\mathrm{C}_{60} \mathrm{H}_{96} \mathrm{O}_{26}$ & 1232.619 & 1232.619 & 1277.6172 & -0.01 & $+\mathrm{HCOO}$ \\
\hline 20 & 4.83 & Wilfoside K 1GG & $\mathrm{C}_{70} \mathrm{H}_{106} \mathrm{O}_{29}$ & 1410.682 & 1410.682 & 1455.6802 & 0 & $+\mathrm{HCOO}$ \\
\hline 21 & 4.93 & Otophylloside L & $\mathrm{C}_{61} \mathrm{H}_{98} \mathrm{O}_{26}$ & 1246.6346 & 1246.6328 & 1291.631 & -1.42 & $+\mathrm{HCOO}$ \\
\hline 22 & 4.94 & $\begin{array}{l}\text { Caudatin 3-O-B-D- } \\
\text { digitoxopyranoside }\end{array}$ & $\mathrm{C}_{34} \mathrm{H}_{52} \mathrm{O}_{10}$ & 620.356 & 620.3561 & 665.3543 & 0.12 & $+\mathrm{HCOO}$ \\
\hline 23 & 4.94 & Cynanauriculoside D & $\mathrm{C}_{61} \mathrm{H}_{92} \mathrm{O}_{27}$ & 1256.5826 & 1256.5828 & 1301.581 & 0.18 & $+\mathrm{HCOO}$ \\
\hline 24 & 4.99 & Cynauricoside $\mathrm{E}$ & $\mathrm{C}_{58} \mathrm{H}_{92} \mathrm{O}_{23}$ & 1156.6029 & 1156.6019 & 1201.6001 & -0.83 & $+\mathrm{HCOO}$ \\
\hline 25 & 5.08 & Wilfoside $\mathrm{E}$ & $\mathrm{C}_{62} \mathrm{H}_{94} \mathrm{O}_{23}$ & 1206.6186 & 1206.6175 & 1205.6102 & -0.92 & $-\mathrm{H}$ \\
\hline 26 & 5.43 & Wilfoside C 1GG & $\mathrm{C}_{68} \mathrm{H}_{110} \mathrm{O}_{29}$ & 1390.7133 & 1390.7132 & 1435.7114 & -0.06 & $+\mathrm{HCOO}$ \\
\hline 27 & 5.12 & Deacylmetaplexigenin & $\mathrm{C}_{21} \mathrm{H}_{32} \mathrm{O}_{6}$ & 380.2199 & 380.2194 & 379.2121 & -1.23 & $-\mathrm{H}$ \\
\hline 28 & 5.21 & Wilfoside A & $\mathrm{C}_{50} \mathrm{H}_{67} \mathrm{NO}_{14}$ & 905.4562 & 905.4563 & 950.4545 & 0.17 & $+\mathrm{HCOO}$ \\
\hline 29 & 5.3 & Cynauriculoside A & $\mathrm{C}_{70} \mathrm{H}_{108} \mathrm{O}_{24}$ & 1332.7231 & 1332.7209 & 1377.7191 & -1.59 & $+\mathrm{HCOO}$ \\
\hline 30 & 5.34 & Cynauricoside I & $\mathrm{C}_{49} \mathrm{H}_{78} \mathrm{O}_{19}$ & 970.5137 & 970.5143 & 969.507 & 0.57 & $-\mathrm{H}$ \\
\hline 31 & 5.4 & Cynauricoside $\mathrm{C}$ & $\mathrm{C}_{65} \mathrm{H}_{96} \mathrm{O}_{23}$ & 1244.6342 & 1244.6347 & 1289.6329 & 0.36 & $+\mathrm{HCOO}$ \\
\hline 32 & 5.45 & Wilfoside G & $\mathrm{C}_{60} \mathrm{H}_{88} \mathrm{O}_{20}$ & 1128.5869 & 1128.587 & 1173.5852 & 0.1 & $+\mathrm{HCOO}$ \\
\hline 33 & 5.46 & Auriculoside B & $\mathrm{C}_{61} \mathrm{H}_{98} \mathrm{O}_{24}$ & 1214.6448 & 1214.6455 & 1259.6437 & 0.54 & $+\mathrm{HCOO}$ \\
\hline 34 & 5.46 & Cynandione D & $\mathrm{C}_{32} \mathrm{H}_{24} \mathrm{O}_{10}$ & 568.1369 & 568.1372 & 567.1299 & 0.44 & $-\mathrm{H}$ \\
\hline 35 & 5.53 & Wilfoside D1N & $\mathrm{C}_{56} \mathrm{H}_{84} \mathrm{O}_{19}$ & 1060.5607 & 1060.5605 & 1105.5587 & -0.19 & $+\mathrm{HCOO}$ \\
\hline 36 & 5.57 & $\begin{array}{l}\text { Caudatin 3-O-B-D- } \\
\text { cymaropyranoside }\end{array}$ & $\mathrm{C}_{35} \mathrm{H}_{54} \mathrm{O}_{10}$ & 634.3717 & 634.3719 & 679.3701 & 0.36 & $+\mathrm{HCOO}$ \\
\hline 37 & 5.57 & Cynanauriculoside II & $\mathrm{C}_{77} \mathrm{H}_{118} \mathrm{O}_{30}$ & 1522.7708 & 1522.7725 & 1567.7707 & 1.11 & $+\mathrm{HCOO}$ \\
\hline 38 & 5.59 & Wilfoside $\mathrm{H}$ & $\mathrm{C}_{53} \mathrm{H}_{76} \mathrm{O}_{17}$ & 984.5083 & 984.5082 & 1029.5064 & -0.07 & $+\mathrm{HCOO}$ \\
\hline 39 & 5.6 & Cyanoauriculoside B & $\mathrm{C}_{66} \mathrm{H}_{100} \mathrm{O}_{25}$ & 1292.6554 & 1292.6542 & 1291.6469 & -0.89 & $-\mathrm{H}$ \\
\hline 40 & 5.65 & Cynauricoside A & $\mathrm{C}_{51} \mathrm{H}_{74} \mathrm{O}_{16}$ & 942.4977 & 942.4977 & 987.4959 & 0.05 & $+\mathrm{HCOO}$ \\
\hline 41 & 5.68 & Cynauricoside B & $\mathrm{C}_{63} \mathrm{H}_{94} \mathrm{O}_{22}$ & 1202.6237 & 1202.624 & 1247.6222 & 0.25 & $+\mathrm{HCOO}$ \\
\hline 42 & 5.69 & Cynanauriculoside $\mathrm{F}$ & $\mathrm{C}_{60} \mathrm{H}_{90} \mathrm{O}_{20}$ & 1130.6025 & 1130.6018 & 1175.6 & -0.62 & $+\mathrm{HCOO}$ \\
\hline 43 & 5.71 & Wilfoside B & $\mathrm{C}_{48} \mathrm{H}_{70} \mathrm{O}_{14}$ & 870.4766 & 870.4804 & 915.4786 & 4.24 & $+\mathrm{HCOO}$ \\
\hline 44 & 5.78 & Wilfoside K1N & $\mathrm{C}_{58} \mathrm{H}_{86} \mathrm{O}_{19}$ & 1086.5763 & 1086.5751 & 1131.5733 & -1.06 & $+\mathrm{HCOO}$ \\
\hline 45 & 5.88 & Wilfoside D & $\mathrm{C}_{55} \mathrm{H}_{82} \mathrm{O}_{20}$ & 1062.5399 & 1062.5396 & 1107.5379 & -0.27 & $+\mathrm{HCOO}$ \\
\hline 46 & 5.9 & Cyanoauriculoside C & $\mathrm{C}_{62} \mathrm{H}_{94} \mathrm{O}_{22}$ & 1190.6237 & 1190.623 & 1189.6157 & -0.57 & $-\mathrm{H}$ \\
\hline 47 & 5.98 & Cynauricoside G & $\mathrm{C}_{56} \mathrm{H}_{90} \mathrm{O}_{22}$ & 1114.5924 & 1114.5928 & 1113.5855 & 0.34 & $-\mathrm{H}$ \\
\hline 48 & 5.99 & Wilfoside C1G & $\mathrm{C}_{62} \mathrm{H}_{100} \mathrm{O}_{24}$ & 1228.6605 & 1228.6604 & 1227.6531 & -0.08 & $-\mathrm{H}$ \\
\hline 49 & 6.04 & $\begin{array}{l}\text { Kidjoranin 3-O- } \beta \text {-D- } \\
\text { digitoxopyranoside }\end{array}$ & $\mathrm{C}_{36} \mathrm{H}_{48} \mathrm{O}_{10}$ & 640.3247 & 640.3246 & 639.3173 & -0.21 & $-\mathrm{H}$ \\
\hline 50 & 6.05 & Cynanauriculoside I & $\mathrm{C}_{76} \mathrm{H}_{116} \mathrm{O}_{30}$ & 1508.7551 & 1508.7555 & 1553.7537 & 0.2 & $+\mathrm{HCOO}$ \\
\hline 51 & 6.14 & Wilfoside C1N & $\mathrm{C}_{56} \mathrm{H}_{90} \mathrm{O}_{19}$ & 1066.6076 & 1066.6073 & 1111.6055 & -0.34 & $+\mathrm{HCOO}$ \\
\hline 52 & 6.64 & Wilfoside F & $\mathrm{C}_{62} \mathrm{H}_{100} \mathrm{O}_{22}$ & 1196.6706 & 1196.671 & 1241.6692 & 0.33 & $+\mathrm{HCOO}$ \\
\hline 53 & 7.17 & Daucosterol & $\mathrm{C}_{35} \mathrm{H}_{60} \mathrm{O}_{6}$ & 576.439 & 576.4387 & 621.4369 & -0.41 & $+\mathrm{HCOO}$ \\
\hline 54 & 7.58 & 9,12,15-Octadecatrienoic acid & $\mathrm{C}_{18} \mathrm{H}_{30} \mathrm{O}_{2}$ & 278.2246 & 278.2245 & 277.2172 & -0.23 & $-\mathrm{H}$ \\
\hline 55 & 8.32 & Metaplexigenin & $\mathrm{C}_{23} \mathrm{H}_{34} \mathrm{O}_{7}$ & 422.2305 & 422.2308 & 421.2235 & 0.83 & $-\mathrm{H}$ \\
\hline 56 & 8.33 & Linoleic acid & $\mathrm{C}_{18} \mathrm{H}_{32} \mathrm{O}_{2}$ & 280.2402 & 280.2402 & 279.233 & -0.01 & $-\mathrm{H}$ \\
\hline
\end{tabular}




\begin{tabular}{|c|c|c|c|c|c|c|c|c|}
\hline 57 & 9.09 & 3-O-methyl-caudatin & $\mathrm{C}_{29} \mathrm{H}_{44} \mathrm{O}_{7}$ & 504.3087 & 504.3078 & 549.306 & -1.72 & $+\mathrm{HCOO}$ \\
\hline 58 & 9.11 & Hexadecanoic acid & $\mathrm{C}_{16} \mathrm{H}_{32} \mathrm{O}_{2}$ & 256.2402 & 256.2402 & 255.233 & -0.01 & $-\mathrm{H}$ \\
\hline 59 & 9.19 & Oleic acid & $\mathrm{C}_{18} \mathrm{H}_{34} \mathrm{O}_{2}$ & 282.2559 & 282.2559 & 281.2486 & 0.04 & $-\mathrm{H}$ \\
\hline 60 & 9.6 & Sarcostin & $\mathrm{C}_{21} \mathrm{H}_{34} \mathrm{O}_{6}$ & 382.2355 & 382.2346 & 381.2274 & -2.37 & $-\mathrm{H}$ \\
\hline 61 & 9.89 & Gagaminine & $\mathrm{C}_{36} \mathrm{H}_{43} \mathrm{NO}_{8}$ & 617.2989 & 617.2996 & 616.2923 & 1.22 & $-\mathrm{H}$ \\
\hline 62 & 10.17 & Octadecanoic acid & $\mathrm{C}_{18} \mathrm{H}_{36} \mathrm{O}_{2}$ & 284.2715 & 284.2716 & 283.2643 & 0.15 & $-\mathrm{H}$ \\
\hline 63 & 10.49 & 20-O-salicyl-kidjoranin & $\mathrm{C}_{37} \mathrm{H}_{44} \mathrm{O}_{9}$ & 632.2985 & 632.299 & 631.2917 & 0.71 & $-\mathrm{H}$ \\
\hline 64 & 10.93 & Wilfoside C & $\mathrm{C}_{48} \mathrm{H}_{70} \mathrm{O}_{17}$ & 918.4613 & 918.4611 & 917.4538 & -0.21 & $-\mathrm{H}$ \\
\hline
\end{tabular}

Table 1: The in-house library of various metabolites in $\mathrm{CW}$ and CA.

\begin{tabular}{|c|c|c|c|c|c|c|c|c|c|}
\hline No. & Biomarkers & & RT (min) & $\begin{array}{l}\text { Molecular } \\
\text { formula }\end{array}$ & $\begin{array}{c}\text { Expected } \\
\text { neutral mass } \\
\text { (Da) }\end{array}$ & $\begin{array}{c}\text { Observed } \\
\text { neutral mass } \\
\text { (Da) }\end{array}$ & $\begin{array}{l}\text { QTOF/MS } \\
\text { (ESI-) } m / z\end{array}$ & $\begin{array}{c}\text { Mass } \\
\text { accuracy } \\
(p p m)\end{array}$ & Adducts \\
\hline 1 & $\mathrm{CW}$ unique marker 1 & Wilfoside C 1GG & 5.43 & $\mathrm{C}_{68} \mathrm{H}_{110} \mathrm{O}_{29}$ & 1390.7133 & 1390.7132 & 1435.7114 & -0.06 & $+\mathrm{HCOO}$ \\
\hline 2 & $\mathrm{CW}$ unique marker 2 & Unknown & 6.23 & $\mathrm{C}_{76} \mathrm{H}_{124} \mathrm{O}_{30}$ & 1516.8177 & 1516.8189 & 1561.8158 & 0.79 & +HCOO \\
\hline 3 & $\mathrm{CW}$ unique marker 3 & Unknown & 6.17 & $\mathrm{C}_{71} \mathrm{H}_{108} \mathrm{O}_{25}$ & 1360.718 & 1360.7202 & 1405.7179 & 1.62 & $+\mathrm{HCOO}$ \\
\hline 4 & $\mathrm{CW}$ unique marker 4 & Unknown & 5.89 & $\mathrm{C}_{69} \mathrm{H}_{112} \mathrm{O}_{27}$ & 1372.7391 & 1372.7417 & 1417.732 & 1.87 & $+\mathrm{HCOO}$ \\
\hline 5 & CW unique marker 5 & Unknown & 6.31 & $\mathrm{C}_{77} \mathrm{H}_{118} \mathrm{O}_{28}$ & 1490.781 & 1490.7831 & 1535.7826 & 1.45 & $+\mathrm{HCOO}$ \\
\hline 6 & $\mathrm{CW}$ unique marker 6 & Unknown & 6.905 & $\mathrm{C}_{78} \mathrm{H}_{120} \mathrm{O}_{28}$ & 1504.7966 & 1504.7958 & 1549.7952 & -0.55 & $+\mathrm{HCOO}$ \\
\hline 7 & $\mathrm{CW}$ unique marker 7 & Unknown & 7.44 & $\mathrm{C}_{70} \mathrm{H}_{114} \mathrm{O}_{25}$ & 1354.7649 & 1354.7643 & 1399.7622 & 1.25 & $+\mathrm{HCOO}$ \\
\hline 8 & CA unique marker 1 & Unknown & 6.26 & $\mathrm{C}_{72} \mathrm{H}_{110} \mathrm{O}_{25}$ & 1374.7336 & 1374.7334 & 1419.7315 & 1.06 & $+\mathrm{HCOO}$ \\
\hline 9 & CA unique marker 2 & Unknown & 3.19 & $\mathrm{C}_{49} \mathrm{H}_{80} \mathrm{O}_{18}$ & 956.5345 & 956.5343 & 1001.5321 & -0.13 & $+\mathrm{HCOO}$ \\
\hline 10 & CA unique marker 3 & Cynauricoside E & 4.99 & $\mathrm{C}_{58} \mathrm{H}_{92} \mathrm{O}_{23}$ & 1156.6029 & 1156.6019 & 1201.6001 & -0.83 & $+\mathrm{HCOO}$ \\
\hline 11 & CA unique marker 4 & Unknown & 4.58 & $\mathrm{C}_{51} \mathrm{H}_{82} \mathrm{O}_{19}$ & 998.545 & 998.5433 & 1043.5408 & -0.86 & $+\mathrm{HCOO}$ \\
\hline 12 & ${ }^{*} \mathrm{BS}$ marker 1 & Unknown & 6.71 & $\mathrm{C}_{70} \mathrm{H}_{114} \mathrm{O}_{25}$ & 1354.7649 & 1354.7675 & 1399.7622 & 1.25 & $+\mathrm{HCOO}$ \\
\hline 13 & BS marker 2 & Wilfoside $\mathrm{K} 1 \mathrm{~N}$ & 5.78 & $\mathrm{C}_{58} \mathrm{H}_{86} \mathrm{O}_{19}$ & 1086.5763 & 1086.5751 & 1131.5733 & -1.06 & $+\mathrm{HCOO}$ \\
\hline 14 & BS marker 3 & Wilfoside $\mathrm{C} 1 \mathrm{~N}$ & 6.14 & $\mathrm{C}_{56} \mathrm{H}_{90} \mathrm{O}_{19}$ & 1066.6076 & 1066.6073 & 1111.6055 & -0.34 & $+\mathrm{HCOO}$ \\
\hline
\end{tabular}

Table 2: The list of biomarkers to discriminate $\mathrm{CW}$ and $\mathrm{CA}$ ( ${ }^{*}$ Both sides).

CAs, and the bar graph of 14 biomarkers validation was represented in Figure $4 \mathrm{~B}$. As a result, the additional analysis of 14 biomarkers showed the almost similar results with previous analysis. Although the fold change of Biomarker 12,13, and 14 was altered, CA showed the higher abundance of them.

\section{Conclusion}

In this study, metabolomics approach based on UPLC-QTOF/MS provided the effective discrimination of $\mathrm{CW}$ and $\mathrm{CA}$. By the optimal LC/MS conditions, the fast and sensitive analysis of 64 metabolites in CW and CA were successfully performed. In the PCA and PLS-DA, not only two groups of $\mathrm{CW}$ and CA but also their mixture samples having different ratio were differentiated well. Next, OPLS-DA and S-plot were also applied for the selection of biomarkers to discriminate $\mathrm{CW}$ and CA. Based on the quantification of 14 selected molecules, we determined $7 \mathrm{CW}$ unique, $4 \mathrm{CA}$ unique, and 3 both sides biomarkers. Our results indicated the UPLC-QTOF/MS based metabolite profiling is promising to differentiate $\mathrm{CW}$ and $\mathrm{CA}$ that have morphological similarity. Hence, this work is of great importance to prevent the misuse of CW and CA especially in the Korean herbal market.

\section{Acknowledgements}

This work was carried out with the support of "Cooperative Research Program for Agriculture Science \& Technology Development (Project No. PJ01136203)" Rural Development Administration, Republic of Korea.

\section{References}

1. Brown PD, Tokuhisa JG, Reichelt M, Gershenzon J (2003) Variation of glucosinolate accumulation among different organs and developmental stages of Arabidopsis thaliana. Phytochem 62: 471-481.

2. Choi DH, Lee YJ, Kim JS, Kang DG, Lee HS, et al. (2012a) Cynanchum wilfordii ameliorates hypertension and endothelial dysfunction in rats fed with high fat cholesterol diets. Immunopharmacol Immunotoxicol 34: 4-11.

3. Choi DH, Lee YJ, Oh HC, Cui YL, Kim JS, et al. (2012b) Improved Endothelial Dysfunction by Cynanchum wilfordii in Apolipoprotein $\mathrm{E}^{-/-}$Mice Fed a High Fat/ Cholesterol Diet. J Med Food 15: 169-179.

4. Gunes A, Inal A (2007) Salicylic acid induced changes on some physiological parameters symptomatic for oxidative stress and mineral nutrition in maize (Zea mays L.) grown under salinity. J Plant Physiol 164: 728-736.

5. Gu XJ, Yao N, Qian SH, Li YB, Li P, et al. (2009) Four new C21 steroidal glycosides from the roots of Cynanchum auriculatum. Hel Chim Acta 92: 88-97.

6. Jiang YF, Choi HG, Li Y, Park YM, Lee JH, et al. (2011) Chemical Constituents of Cynanchum wilfordii and the Chemotaxonomy of Two Species of the Family Asclepiadacease, C. wilfordii and C. auriculatum. Arch Pharm Res 34: 20212027.

7. KFDA (2008) The $9^{\text {th }}$ Korean Herbal Pharmacopoeia

8. Kim MS, Baek JH, Park JA, Hwang BY, Kim SE, et al. (2005) Wilfoside $\mathrm{K} 1 \mathrm{~N}$ isolated from Cynanchum wilfordii inhibits angiogenesis and tumor cell invasion. Int J Oncol 26: 1533-1539.

9. Choi KA (2015) Fake medicine hits retail investors hard. The Korea Times.

10. Lee DW, Kim CH, Le DU (2001) Effect of Culture Conditions on the Biosynthesis of Gagaminine, a Potent Antioxidant from the Roots of Cynanchum wilfordii. Bio Pharm Bull 24: 1451-1453.

11. Lee DY, Kim JK, Shrestha S, Seo KH, Lee YH, et al. (2013) Quality Evaluation of Panax ginseng Roots Using a Rapid Resolution LC-QTOF/MS-Based Metabolomics Approach. Molecules 18: 14849-14861.

12. Li Y, Piao D, Zhang H, Woo MH, Lee JH, et al. (2013) Quality assessment and discrimination of the roots of Cynanchum auriculatum and Cynanchum wilfordii by HPLC-UV analysis. Arch Pharm Res 36: 335-344.

13. Liede S, Tauber A (2002) Circumscriptionof the Genus Cynanchum (Apocynaceae-Asclepiadoideae). Am Soc Plant Taxonomists 27: 789-800.

14. Liu JH, Kitashiba H, Wang J, Ban Y, Moriguchi T, et al. (2007) Polyamines and their ability to provide environmental stress tolerance to plants. Plant Biotechnol 24: 117-126. 
Citation: Lee JW, Ji SH, Lee MK, Kim GS, Ahn YS, et al. (2015) Metabolomics Based on UPLC-QTOF/MS Applied for the Discrimination of Cynanchum wilfordii and Cynanchum auriculatum. Metabolomics 5: 152. doi:10.4172/2153-0769.1000152

15. Moon BC, Choo BK, Cheon MS, Yoon T, Ji Y, et al. (2010) Rapid molecular authentication of three medicinal plant Cynanchum wilfordii, Cynanchum auriculatum, and Polygonum multiflorum (Fallopia multiflorum), by the development of RAPD-derived SCAR markers and multiplex-PCR. Plant Biotechnol Rep 4: 1-7.

16. Qi LW, Gu XJ, Li P, Liang Y, Hao H, et al. (2009). Structural characterization of pregnane glycosides from Cynanchum auriculatum by liquid chromatography on a hybrid ion trap time-of-flight mass spectrometer. Rapid Commun Mass Spectrom 23: 2151-2160.

17. Ryuk JA, Lee HW, Ju YS, Ko BS (2014) Monitoring and Identification of Cynanchum wilfordii and Cynanchum auriculatum by Using Molecular Markers and Real-Time Polymerase Chain Reaction. J Korean Soc App BI 57: 245-251.

18. Schauer N, Fernie AR (2006) Plant metabolomics: towards biological function and mechanism. Trends Plant Sci 11: 508-516.

19. Shan L, Liu RH, Shen YH, Zhang WD, Zhang C, et al. (2006) Gastroprotective effect of a traditional Chinese herbal drug "Baishouwu" on experimental gastric lesions in rats. J Ethnopharmacol 107: 389-394.

20. Steinmann D, Ganzera M (2011) Recent advances on HPLC/MS in medicinal plant analysis. J Pharm Biomed Anal 55: 744-757.

21. Sultana T, Stecher G, Mayer R, Trojer L, Qureshi MN, et al. (2008) Quality Assessment and Quantitative Analysis of Flavonoids from Tea Samples of Different Origins by HPLC-DAD-ESI-MS. J Agric Food Chem 56: 3444-3453.
22. Sumner LW, Mendes P, Dixon RA (2003) Plant metabolomics: large-scale phytochemistry in the functional genomics era. Phytochem 62: 817-836.

23. Sun L, Li J, Zhou K, Zhang M, Yang J, et al. (2013) Metabolomic analysis reveals metabolic disturbance in the cortex and hippocampus of subchronic MK-801 treated rats. PLoS ONE 8: e60598.

24. Trygg J, Holmes E, Lundstedt T (2007) Chemometrics in metabonomics. J Proteome Res 6: 469-479.

25. De Vos RC, Moco S, Lommen A, Keurentjes JJ, Bino RJ, et al. (2007) Untargeted large-scale plant metabolomics using liquid chromatography coupled to mass spectrometry. Nat Protoc 2: 778-791.

26. Wang YQ, Zhang SJ, Lu H, Yang B, Ye LF, et al. (2013) A C21-Steroidal Glycoside Isolated from the Roots of Cynanchum auriculatum Induces Cell Cycle Arrest and Apoptosis in Human Gastric Cancer SGC-7901 Cells. Evid Based Complement Alternat Med 1-7.

27. Wang M, Yang X, Wang F, Li R, Ning H, et al. (2013b) Calcium-deficiency assessment and biomarker identification by an integrated urinary metabolomics analysis. BMC Medicine 11:86.

28. Xiang, WJ, Ma L (2009) C21 steroidal glycosides from Cynanchum wilfordii. $\mathrm{He}$ Chim Acta 92: 2659-2674.

29. Yang QX, Ge YC (2011) Cynanauriculoside C-E, three new antidepressant pregnane glycosides from Cynanchum auriculatum. Phytochem Lett 4: 170175. 